\title{
Geographical clustering of cases of infection with moxifloxacin-resistant Clostridium difficile PCR- ribotypes 012, 017 and 046 in Sweden, 2008 and 2009
}

\author{
T Åkerlund (Thomas.Akerlund@smi.se) ${ }^{1}$, I Alefjord ${ }^{1}$, U Dohnhammar ${ }^{1}$, J Struwe ${ }^{1}$, T Norén ${ }^{2}$, K Tegmark-Wisell ${ }^{1}$, the Swedish \\ C. difficile Study Group ${ }^{3}$ \\ 1. Swedish Institute for Infectious Disease Control, Solna, Sweden \\ 2. Department of Infectious Diseases, Örebro University Hospital, Örebro, Sweden \\ 3. Members are listed at the end of the article
}

Citation style for this article:

Akerlund T, Alefjord I, Dohnhammar U, Struwe J, Norén T, Tegmark-Wisell K, the Swedish C. difficile Study Group. Geographical clustering of cases of infection with moxifloxacin-resistant Clostridium difficile PCR-ribotypes 012, 017 and 046 in Sweden, 2008 and 2009. Euro Surveill. 2011;16(10):pii=19813. Available online:

http://www.eurosurveillance.org/ViewArticle.aspx?Articleld=19813

Article published on 10 March 2011

We report the results of two nationwide surveillance studies of Clostridium difficile infection conducted during 2008 and 2009 in Sweden. The first study aimed to identify and quantify the proportion of C. difficile isolates with decreased susceptibility to moxifloxacin, particularly those of PCR-ribotype 027. From December 2007 to September 2008, 20 of 28 regional laboratories sent 585 isolates to the Swedish Institute for Infectious Disease Control for typing. A majority of the isolates ( 454 of $585 ; 78 \%$ ) belonged to four PCR ribotypes (012, SE37, 017 and 046), all clustered in geographical regions. Only two type 027 isolates were found, both from the same patient. In the second study, involving all 28 regional laboratories, all consecutive $C$. difficile isolates collected during two time periods in $2009(n=364)$ were typed and tested for susceptibility to clindamycin, erythromycin, moxifloxacin, metronidazole and vancomycin. The three most common PCR ribotypes were SE21, 001 and 020 (22\% of all isolates). Types 012, 017, and 046 were geographically clustered and associated with decreased susceptibility to moxifloxacin, clindamycin and erythromcin. The extent of moxifloxacin prescription was highly variable among counties, indicating a need for careful monitoring of prescription rates to follow its role in $C$. difficile epidemiology.

\section{Introduction}

Clostridium difficile infection is a common nosocomial problem in elderly patients following antibiotic treatment [1]. C. difficile is typically isolated from faeces of $1-5 \%$ of healthy individuals, but colonisation increases upon admission to hospitals. Hospital-based studies performed in 1999 to 2001 showed that nosocomial spread of $C$. difficile was rare in Swedish hospitals in which infection control routines were implemented, although there were small outbreaks associated with multiresistant PCR-ribotype 012/SE17 [2-4]. Many outbreaks involving other $C$. difficile types have been reported in Europe and the rest of the world [5-8], particularly those caused by moxifloxacin-resistant PCR-ribotype 027/PFGE NAP1 [9-17]. The expansion of certain C. difficile types during 2004 to 2008 prompted us to initiate a broader nationwide $C$. difficile surveillance strategy in Sweden. First, in an aim to find virulent type 027 , a screening of $C$. difficile isolates with reduced susceptibility to moxifloxacin was performed during 2008. Second, a surveillance programme, including epidemiological typing and antibiotic susceptibility testing, was launched in 2009. Third, a web-based system for continuous voluntary laboratory reporting was initiated in 2009 . This article presents the epidemiological situation of $C$. difficile in Sweden in 2008 and 2009 with respect to the occurrence of various PCR ribotypes and their antibiotic susceptibility.

\section{Methods}

Screening of $C$. difficile isolates with decreased susceptibility to moxifloxacin (2008)

An invitation to participate in the study, including instructions, methods and study protocol, was sent to all 28 regional clinical laboratories in Sweden. Faecal specimens sent by the clinicians for routine C. difficile detection were tested in the regional laboratories according to their standard methodology (ELISA/ EIA was the most commonly used method, in 24 of the 28 laboratories, followed by cell cytotoxicity assay). Sample material that was positive for $C$. difficile was inoculated anaerobically on taurocholate-cefoxitincycloserine-fructose agar (TCCFA) for 48 hours and toxigenic $C$. difficile colonies were subcultured on blood agar. Susceptibility to moxifloxacin was tested using disc diffusion ( $5 \mu \mathrm{g}$ ) on IsoSensitest agar (Oxoid, United Kingdom) supplemented with 5\% defibrinated horse blood and $20 \mu \mathrm{g} / \mathrm{ml}$ beta-NAD incubated at $36{ }^{\circ} \mathrm{C}$ for 48 hours. $C$. difficile strains with an inhibition zone diameter $>16$ mm (ATCC9689) and 6 mm (Ö07-1702) were used as controls. All $C$. difficile isolates with zone diameter $\$ 16 \mathrm{~mm}$ were sent to the Swedish Institute for Infectious Disease Control for typing. A protocol with 
strain number, diameter of the inhibition zone, and, if possible, the total number of screened isolates were included each shipment. Upon arrival, samples were inoculated on both TCCFA and blood agar and incubated anaerobically at $36^{\circ} \mathrm{C}$ for 48 hours. Isolated strains were verified for susceptibility to moxifloxacin using the disc diffusion method described above and Etest (AB Biodisk, Sweden). Of 641 sent samples, 37 were excluded because $C$. difficile could not be isolated and/ or the sample was contaminated; a further 19 isolates

\section{FIGURE 1}

Proportion of Clostridium difficile PCR ribotypes ${ }^{\mathrm{a}}$ with decreased susceptibility to moxifloxacin, Sweden, 2008 $(\mathrm{n}=585)$

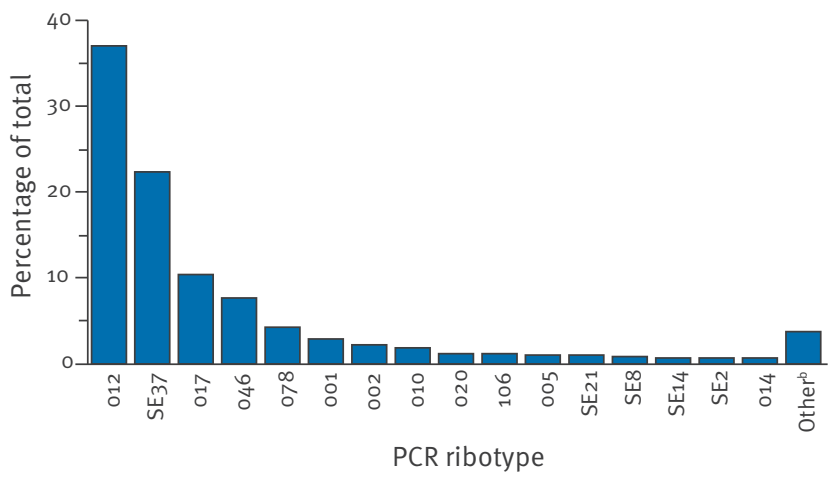

a The three-digit international nomenclature is used for typing, or when reference isolates are missing, SE-type is used.

${ }^{b}$ Ribotypes represented by fewer than three isolates per type. were omitted due to an inhibition zone diameter >16 $\mathrm{mm}$, giving a final $585 \mathrm{C}$. difficile isolates. The study period was from 7 December 2007 to 1 September 2008. Since no patient data were included, we could not judge how many patients or how many cases of C. difficile infection there were during the study period.

National surveillance typing (2009)

An invitation to participate in the surveillance programme, including methods and study protocol, was sent to all 28 regional Swedish laboratories. All consecutive strains isolated from $C$. difficile-positive samples obtained through routine detection during 9-15 April and 21-27 September 2009 were sent to the Swedish Institute for Infectious Disease Control for typing and susceptibility testing for moxifloxacin, erythromycin, clindamycin, metronidazole and vancomycin. Of 432 samples sent, 40 were excluded because they were contaminated or not viable. Of the remaining 392 isolates, 28 were not analysed because their dates of isolation did not comply with the inclusion criteria above, giving a final total of 364 isolates.

Susceptibility testing was performed using Etest on Mueller-Hinton agar medium (BD Diagnostics) at $35^{\circ} \mathrm{C}$ for 48 hours. A bacterial density of McFarland 1 was used to obtain a next-to-confluent layer of C. difficile bacteria. There were no significant differences in minimum inhibitory concentration (MIC) values using Mueller-Hinton or IsoSensitest agar (data

\section{FIGURE 2}

Geographical distribution of dominating Clostridium difficile PCR ribotypes with decreased susceptibility to moxifloxacin, Sweden, $2008(n=454)$

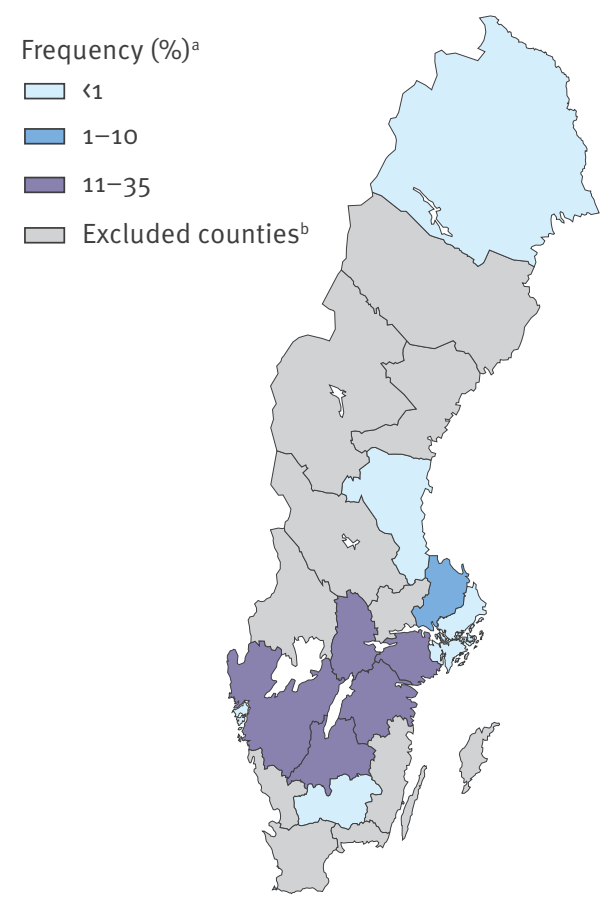

012

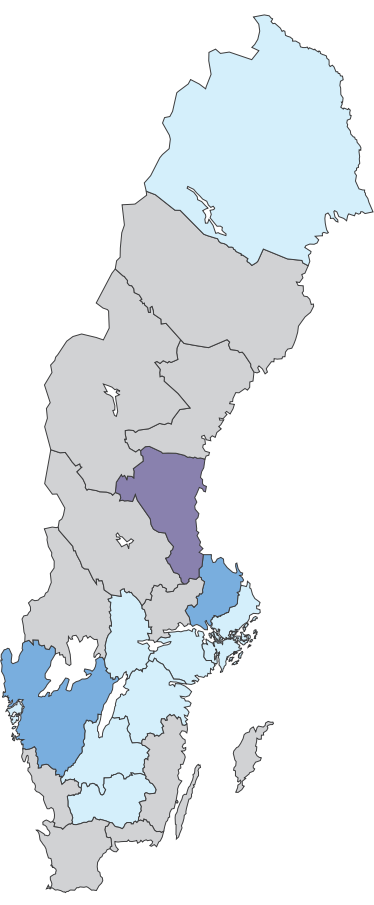

017

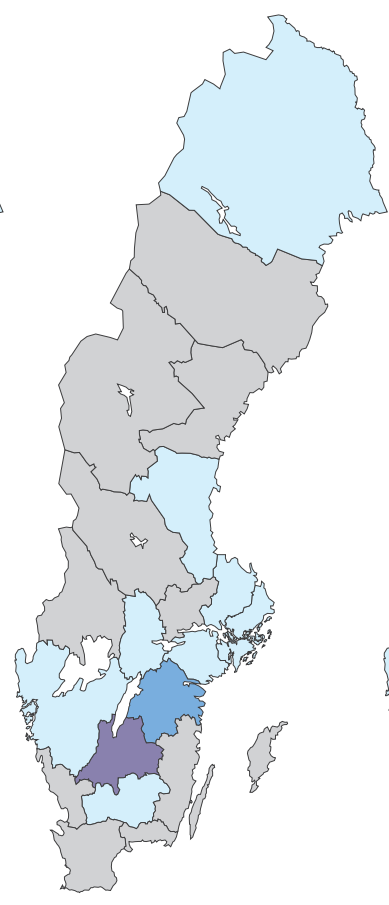

046

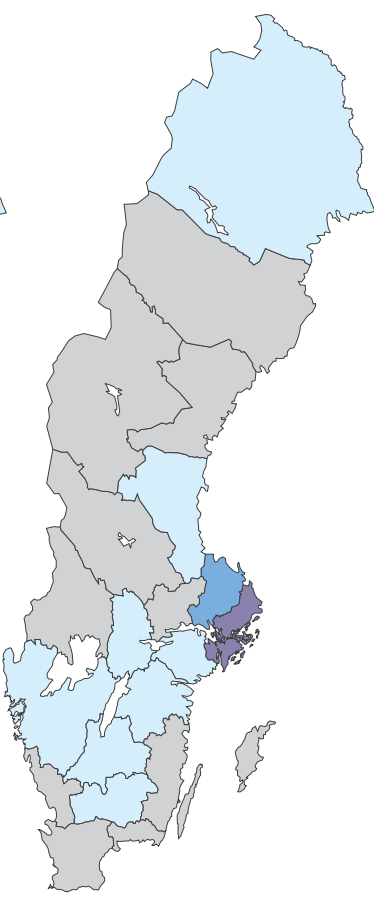

SE37

a The frequency is calculated as the number of isolates of the indicated type divided by the total number of screened isolates in each county multiplied by 100 .

${ }^{b}$ Due to missing numbers of total screened isolates during the study period from some laboratories, calculation of frequency was only possible for 10 of the 21 counties. 
not shown). Breakpoints were chosen according to the European Committee on Antimicrobial Susceptibility Testing (EUCAST) tentative ecological cut-off for detection of isolates with resistance mechanisms, as suggested by the European Study Group for C. difficile [18].

\section{PCR ribotyping}

PCR ribotyping was performed according to the method of Stubbs et al. [8], with modifications described in Svenungsson et al. [4]. Reference isolates were obtained from the Cardiff-European Centre for Disease Prevention and Control (ECDC) collection of $C$. difficile strains (obtained from Ed J. Kuijper, Leiden University Center, Leiden, the Netherlands). Bionumerics software version 6.1 (Applied Maths NV, Sint-Martens-Latem, Belgium) was used for the analysis. The three-digit international nomenclature was used for typing or, when reference isolates were missing, an SE-type was given.

\section{Prescription of antibiotics}

Sales data of antibiotics were obtained from Apotekens Service $A B$, which is responsible for compilation of all

\section{FIGURE 3}

Proportion of Clostridium difficile PCR ribotypes ${ }^{\text {, }}$ Sweden, 2009 ( $n=364)$

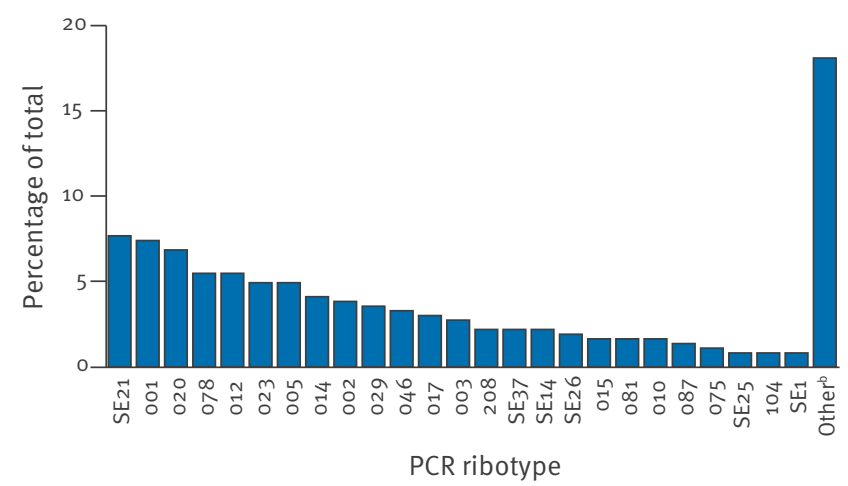

a The three-digit international nomenclature is used for typing, or when reference isolates are missing, SE-type is used.

${ }^{b}$ Ribotypes represented by fewer than three isolates per type. drug statistics, including sales, in Sweden. The data include antibiotics prescribed to patients as well as sales to hospitals and other healthcare providers.

\section{Statistical methods}

Fisher's exact test and chi-square tests were performed to examine differences in geographical distribution of ribotypes using $R$ v. 2.10.1. Kaleidagraph v. 4.02 (Synergy software) was used for data management and graphics. To avoid type-I error due to multiple statistical tests, a significance threshold of $p=0.005$ was applied.

\section{Results \\ C. difficile isolates with decreased \\ susceptibility against moxifloxacin (2008)}

A total of 20 of the 28 Swedish regional laboratories covering 15 of the 21 of the counties supplied a total of 585 isolates with reduced susceptibility to moxifloxacin. Of the 15 counties, 10 supplied data on the number of screened isolates: 546 of 2,702 isolates (20\%; range: $9-34 \%$ ) had decreased susceptibility to moxifloxacin. Of the 585 isolates (from the 15 laboratories), 454 (78\%) belonged to four PCR ribotypes: 012, SE37, 017 and 046 (Figure 1). Types 012 and 046 were found mainly in the central and southern part of Sweden, while types 017 and SE37 were predominant in the central-east counties of Gävleborg and Stockholm, respectively (Figure 2, shown in purple). The distributions for each of the types 012, 017, 046, 078 and SE37, compared with that of other types, were highly skewed between counties: a chi-square test among counties having more than 10 isolates available for typing gave a $p$ value of 10.001 for each of the types 012, 017, 046, 078 and SE37 (for 9 of the 21 counties). Only two type 027 isolates were found, both from the same patient.

National surveillance typing programme (2009) Of 364 C. difficile isolates supplied by all 28 regional laboratories, type SE21 was found in highest number followed by types 001, 020, 078, 012 and 023 (Figure

\section{FIGURE 4}

PCR ribotype patterns of the Clostridium difficile SE21/014/020 group ${ }^{\text {, }}$, Sweden, 2009 (n=8)

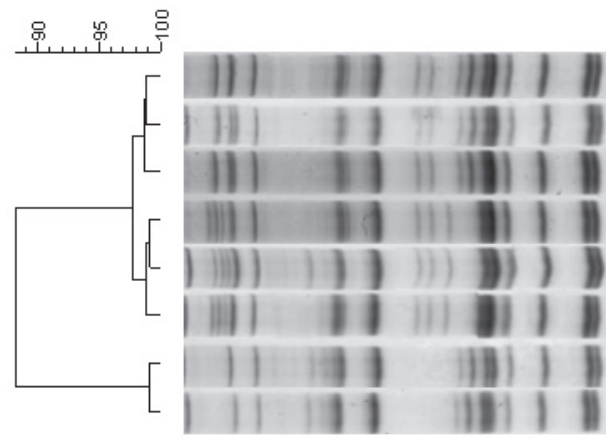

\begin{tabular}{|l|l|}
\hline Strain & PCR ribotype \\
\hline ATCC 43600 & SE21a/o14 \\
\hline NT035 & SE21a \\
\hline NT141 & SE21a \\
\hline NT140 & SE21b \\
\hline R10079 & SE21b/o20 \\
\hline NT094 & SE21b \\
\hline NT020 & SE21 \\
\hline NT042 & SE21 \\
\hline
\end{tabular}

ECDC: European Centre for Disease Prevention and Control; NT: national typing.

a $C$. difficile strains from the 2009 study, designated NT, and the Cardiff-ECDC collection are shown. The dendogram was produced using cluster correlation, Pearson correlation and the unweighted pair group method for arithmetic averages. The scale shows similarity as a percentage. 
3). The PCR ribotype pattern of type SE21 was related to those of types SE21a/014 and SE21b/020 (Figure 4): because of their similarities, this group of ribotypes has sometimes been called the '014/020' group (see Discussion). However, in our study we judged these as separate types. Type 012, 017 and 046 were abundant in the same geographical regions as in 2008 and the geographical distributions of these types were significantly asymmetric (Figure 5) (p<0.001 each, Fisher's exact test; all 21 counties). Other types were not clustered or were only weakly so, for example, 001 $(p=0.95), 014(p=0.022), 020(p=0.012), 023(p=0.71)$, $078(p=0.31), \operatorname{SE} 21(p=0.14)$ and SE37 $(p=0.23)$. One type 027 isolate was detected but it showed a MIC of $<4$ $\mathrm{mg} / \mathrm{L}$ against moxifloxacin, which is not characteristic for the epidemic and hypervirulent type 027.

In total, 57 of the $364(16 \%)$ isolates showed decreased susceptibility to moxifloxacin (MIC/32 mg/L); all other isolates displayed MIC values between $0.25 \mathrm{mg} / \mathrm{L}$ and $2 \mathrm{mg} / \mathrm{L}$ ). The geographical distribution of isolates with a MIC/32 mg/L was skewed ( $p<0.001$, Fisher's exact test, $n=14$, with counties reporting fewer than 10 isolates excluded) and 46 of 57 isolates belonged to type 012, 017,046 and SE37 (Table). In total, 60 of 364 (16\%) isolates showed decreased susceptibility to clindamycin and, again, a majority ( 46 of 60 ) isolates belonged to type 012, 017, 046 and SE37 (Table). Of the 364 isolates, $62(17 \%)$ showed decreased susceptibility to

\section{FIGURE 5}

Geographical distribution of Clostridium difficile PCR ribotypes associated with decreased moxifloxacin susceptibility in all 21 counties, Sweden, $2009(\mathrm{n}=57)$

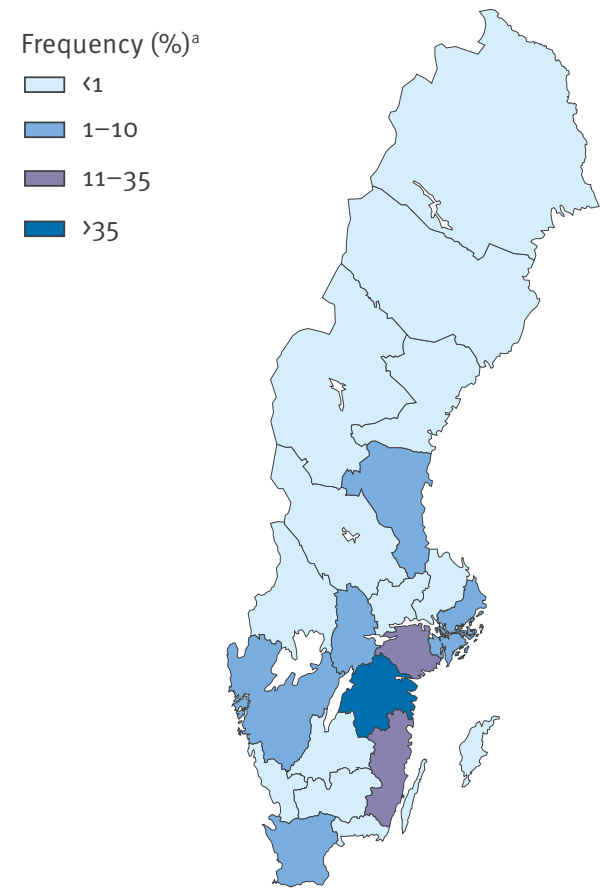

012

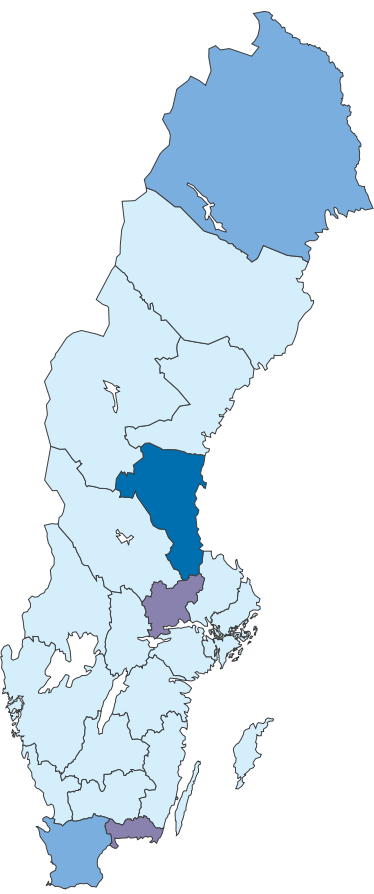

017

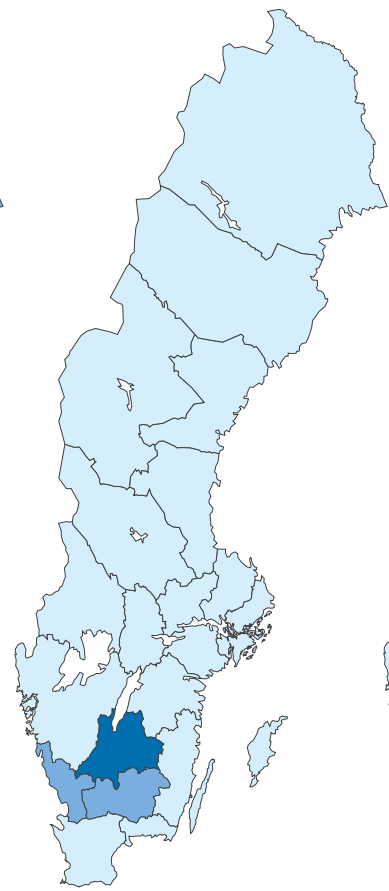

046

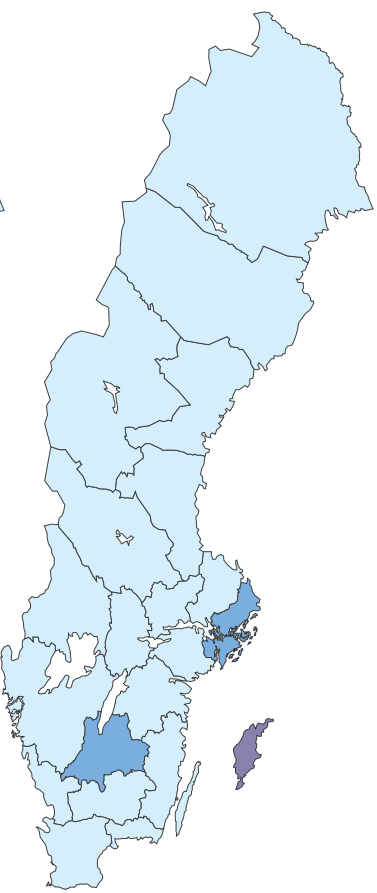

SE37

a The frequency is calculated as the number of isolates of the indicated type divided by the total number of screened isolates for each county multiplied by 100 .

\section{TABLE}

Proportion of Clostridium difficile PCR ribotypes with decreased susceptibility to moxifloxacin, clindamycin and erythromycin, Sweden, $2009(\mathrm{n}=364)$

\begin{tabular}{|c|c|c|c|c|}
\hline \multirow[b]{2}{*}{ PCR ribotype } & \multirow[b]{2}{*}{ Number of isolates tested } & \multicolumn{3}{|c|}{ Number of isolates with decreased antibiotic susceptibility ${ }^{\mathrm{a}}$} \\
\hline & & $\begin{array}{l}\text { Moxifloxacin } \\
\left(\mathrm{MIC}>_{4} \mathrm{mg} / \mathrm{L}\right)\end{array}$ & $\begin{array}{l}\text { Clindamycin } \\
\text { (MIC>16 mg/L) }\end{array}$ & $\begin{array}{l}\text { Erythromycin } \\
\text { (MIC } 2 \mathrm{mg} / \mathrm{L} \text { ) }\end{array}$ \\
\hline 012 & 20 & 19 & 18 & 15 \\
\hline 017 & 11 & 10 & 11 & 10 \\
\hline 046 & 12 & 10 & 10 & 10 \\
\hline SE37 & 8 & 7 & 7 & 7 \\
\hline Other & 313 & 11 & 14 & 20 \\
\hline
\end{tabular}

MIC: minimum inhibitory concentration.

a Breakpoints were chosen according to the European Committee on Antimicrobial Susceptibility Testing (EUCAST) tentative ecological cut-off for detection of isolates with resistance mechanisms, as suggested by the European Study Group for C. difficile. 
erythromycin (Table). No isolate was resistant to metronidazole or vancomycin.

\section{Prescription of moxifloxacin in}

Sweden in 2008 and 2009

The mean prescription rate of moxifloxacin per county was 0.020 defined daily dose (DDD) per 1,000 inhabitants per day for 2008 and 2009 . The prescription rate differed markedly between counties (range: $0-0.088$ DDD per 1,000 inhabitants per day) and was highest in the south-east of Sweden (Figure 6). Some of the counties in the south-east also had a high proportion of PCR ribotypes 012 and 046 (Figure 5). However, the prescription rate of moxifloxacin was comparatively low in the counties where types 017 and SE37 dominated.

\section{Discussion and conclusion}

PCR ribotyping has been used for studying $C$. difficile epidemiology for several years, and details of the first large $C$. difficile PCR ribotype library were published by Stubbs et al. in 1999 [8]. When the European Centre for Disease Prevention and Control (ECDC) and the Centre for Infectious Disease Control Netherlands initiated a pan-European C. difficile infection survey (ECDIS) study in 2008 [19], a C. difficile reference strain collection with defined PCR ribotypes was formed (the CardiffECDC collection). One purpose of the collection was to support national laboratories in setting up local typing systems and to aid surveillance studies and international comparisons. We found that a majority of the C. difficile strains in Sweden was represented in this

\section{FIGURE 6}

Extent of prescription of moxifloxacin by county, Sweden, 2008 and 2009

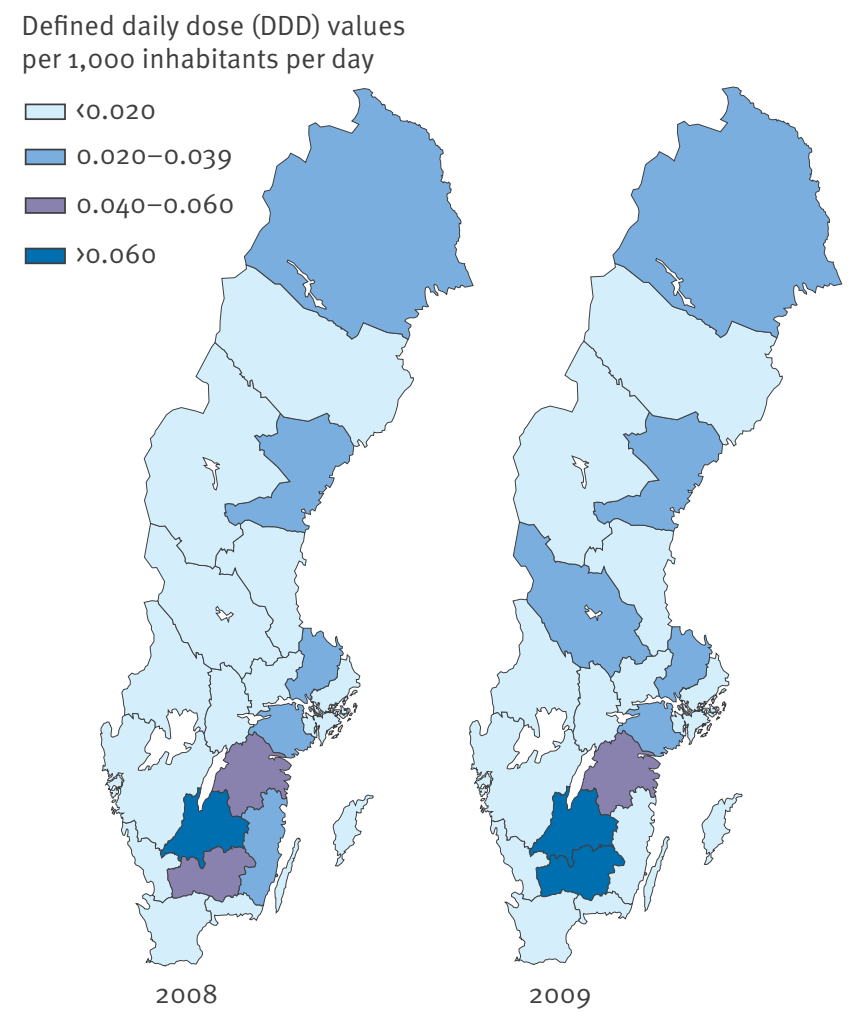

Defined daily dose (DDD) values

per 1,000 inhabitants per day reference strain collection. Exceptions were type SE37, for example, which was confirmed in the ECDIS study as one of six novel types (PCR ribotype 231) [19]. Another unknown type was SE21, which closely resembled types SE21a and SE21b as well as reference strains of PCR-ribotypes 014 and 020 [4]. Type SE21 was verified as a member of the 014/020 group: in total this group comprised $19 \%$ of all C. difficile isolates in our study in Sweden in 2009. The proportion of the 014/020 group among all C. difficile isolates was $16 \%$ in Europe in 2008 [19].

Much interest in recent years has been focused on the worldwide spread of the hypervirulent $C$. difficile type $027[20,21]$. Outbreaks in northern Europe in 2007 to $2009[10-11,13,22]$ prompted us to screen for type 027 isolates with decreased susceptibility to moxifloxacin. Of the 585 isolates analysed during 2008, only two type 027 isolates were detected (from the same patient). Furthermore, since no type 027 isolate with reduced susceptibility to moxifloxacin was identified in 2009, such isolates are probably rare in Sweden (compare with [23]). From previous geographically localised studies in Sweden in 1999 to 2001, the six most common types were 014/SE21, 012, 001, 020, 002 and 005 [2-4]. All these were still among the most common types in 2009. There were thus only small changes in the distribution of major types over a period of 10 years, a result quite different from the shift in strain types that has occurred in England [7]. One exception might be type 078 , which was the fourth most common type in 2009. Type 078 may be an emerging type in Europe and is commonly found in domestic animals, suggesting transmission through the food chain [24-26].

The studies presented here have several weaknesses. All laboratories did not report a full set of data, particularly from the first screening study. This was mostly due to the fact that several laboratories were in the process of setting up culturing methods and were thus unable to supply isolates from the first day of the study period. Also, the two studies were not of identical design: the first aimed to collect consecutive moxifloxacin-resistant isolates during a longer time period and the second collected all isolates during two shorter time periods. In addition, the short study periods in 2009 implies a poor detection of seasonal variability. We also did not ask for detailed information about the number of patients or the number of cases during the study periods - thus the true prevalence could not be calculated. Despite these limitations, the regional clustering of certain types observed in 2008 was confirmed in 2009. Some of the remaining questions will be answered by the voluntary reporting system, but since all laboratories are not yet participating, it is too early draw any conclusions from this system.

The proportion of $C$. difficile isolates with reduced susceptibility to moxifloxacin was $16 \%$ in Sweden 2009 and thus less than half of the $37.5 \%$ reported in Europe in 2005 [5]. Decreased susceptibility to moxifloxacin 
has been found in several $C$. difficile types isolated in Europe and worldwide, and appears to be common in dominant types including 001, 018, 027 and $106 \mathrm{in}$, for example, England [7], Scotland [27], Germany [28] and Italy [5]. We found decreased susceptibility mainly in types 012, 017, 046 and 231/SE37. Type 012 is related to serogroup $C$ [29] and has been reported as a common type in Sweden, Greece and Hungary $[2,19]$ while toxin A-negative, toxin B-positive type 017 has been found to be associated with outbreaks in, for example, Poland, Canada and the Netherlands $[6,30]$. Regarding type $231 / \mathrm{SE} 37$, the proportion of this type was $0.8 \%$ at the Karolinska University Hospital, Huddinge, Sweden, in 1999 [4], but there is no information on whether this type has caused any outbreaks in other countries.

Despite reports of increased prevalence of moxifloxacin resistance in $C$. difficile [5,31-33], including outbreaks of $C$. difficile 027 occurring shortly after replacing levofloxacin with moxifloxacin/gatifloxacin [34], it is currently unclear whether moxifloxacin use implies higher risk for $C$. difficile infection than other commonly used antibiotics [35-38]. Thus, we can neither confirm nor exclude the possibility that moxifloxacin has contributed to the selection of types 046 and 012 in certain Swedish counties. In this context, it should be pointed out that types 012, 017, 046 and 231/SE37 had decreased susceptibility also to clindamycin and erythromycin. Moreover, type 012 was shown to be resistant to many other antibiotics that were not tested in this report [32]. Thus, their success as pathogens may just reflect general selection due to the overall antibiotic use in healthcare settings [7]. Nevertheless, the cause for the variable prescription rates of moxifloxacin in Sweden needs to be investigated further.

In conclusion, in our two nationwide $C$. difficile surveillance studies in Sweden in 2008 and 2009, there was a geographical clustering of PCR-ribotypes 012, 017, 046 and a novel type (231/SE37), suggesting transmission and local outbreaks. Our results support the need for a central European or international $C$. difficile database with capability to continuously report and characterise emerging types, as well as a national surveillance system to monitor and control $C$. difficile incidence, type distribution, resistance pattern and related antibiotic use.

\section{Acknowledgements}

We thank Dr Ed Kuijper for supplying the C. difficile CardiffECDC reference collection.

\section{Members of the Swedish C. difficile Study Group}

T Ahlquist (Värmland County), $M$ Andersson (Gävleborg County), $M$ Bäckman (Aleris Medilab), BM Ellis (Blekinge County), H Göransson (Linköping County), BI Kjellin (Unilabs), A Lagerqvist-Vidh (Uppsala County), B Loré (Dalarna County), T Monsen (Västerbotten County), P Nilsson (Halland County), D Heime ( Västmanland County), M Toepfer (Jönköping County), M Sundqvist (Kronoberg County), M Walder (Skåne County), A Weintraub and B Osterman (Stockholm County), M Ygge (Norrbotten County), C Åhren (Västra Götaland County).

\section{References}

1. Samore MH. Epidemiology of nosocomial Clostridium difficile infection. Compr Ther. 1993;19(4):151-6.

2. Norén, T, Akerlund T, Bäck E, Sjöberg L, Persson I, Alriksson I, et al., Molecular epidemiology of hospital-associated and community-acquired Clostridium difficile infection in a Swedish county. J Clin Microbiol. 2004;42(8):3635-43.

3. Wullt, M, Burman LG, Laurell MH, Akerlund T. Comparison of AP-PCR typing and PCR-ribotyping for estimation of nosocomial transmission of Clostridium difficile. J Hosp Infect. 2003;55(2):124-30.

4. Svenungsson B, Burman LG, Jalakas-Pörnull K, Lagergren A, Struwe J, Akerlund T. Epidemiology and molecular characterization of Clostridium difficile strains from patients with diarrhea: low disease incidence and evidence of limited cross-infection in a Swedish teaching hospital. J Clin Microbiol. 2003;41(9):4031-7.

5. Spigaglia P, Barbanti F, Dionisi AM, Mastrantonio P. Clostridium difficile isolates resistant to fluoroquinolones in Italy: emergence of PCR ribotype 018. J Clin Microbiol. 2010;48(8):2892-6.

6. Pituch H, Brazier JS, Obuch-Woszczatynski P, Wultanska D, Meisel-Mikolajczyk F, Luczak M. Prevalence and association of PCR ribotypes of Clostridium difficile isolated from symptomatic patients from Warsaw with macrolidelincosamide-streptogramin B (MLSB) type resistance. J Med Microbiol. 2006;55(Pt 2):207-13

7. Brazier JS, Raybould R, Patel B, Duckworth G, Pearson A, Charlett A, et al. Distribution and antimicrobial susceptibility patterns of Clostridium difficile PCR ribotypes in English hospitals, 2007-08. Euro Surveill. 2008;13(41): pii=19000. Available from: http://www.eurosurveillance.org/ViewArticle. aspx?Articleld $=19000$

8. Stubbs SL, Brazier JS, O'Neill GL, Duerden BI. PCR targeted to the 16S-23S rRNA gene intergenic spacer region of Clostridium difficile and construction of a library consisting of 116 different PCR ribotypes. J Clin Microbiol. 1999;37(2):461-3.

9. Kleinkauf N, Weiss B, Jansen A, Eckmanns T, Bornhofen B, Küehnen E, et al. Confirmed cases and report of clusters of severe infections due to Clostridium difficile PCR ribotype 027 in Germany. Euro Surveill. 2007;12(46): $\mathrm{pii}=3307$. Available from: http://www.eurosurveillance.org/ViewArticle. aspx?Articleld $=3307$

10. Bacci S, St-Martin G, Olesen B, Bruun B, Olsen KE, Nielsen EM, et al. Outbreak of Clostridium difficile 027 in North Zealand, Denmark, 2008-2009. Euro Surveill. 2009;14(16):pii=19183. Available from: http://www.eurosurveillance.org/ViewArticle. aspx?Articleld $=19183$

11. Kuijper EJ, Barbut F, Brazier JS, Kleinkauf N, Eckmanns T, Lambert ML, et al. Update of Clostridium difficile infection due to PCR ribotype 027 in Europe, 2008. Euro Surveill. 2008;13(31):pii=18942. Available from: http://www. eurosurveillance.org/ViewArticle.aspx?Articleld $=18942$

12. Fenner L, Frei R, Gregory M, Dangel M, Stranden A, Widmer AF. Epidemiology of Clostridium difficile-associated disease at University Hospital Basel including molecular characterisation of the isolates 2006-2007. Eur J Clin Microbiol Infect Dis. 2008.;27(12):1201-7.

13. Lyytikainen O, Mentula S, Könönen E, Kotila S, Tarkka E, Anttila VJ, et al. First isolation of Clostridium difficile PCR ribotype 027 in Finland. Euro Surveill. 2007;12(11):pii=3303. Available from: http://www.eurosurveillance.org/ViewArticle. aspx?Articleld $=3303$

14. Indra A, Huhulescu S, Fiedler A, Kernbichler S, Blaschitz $M$, Allerberger F. Outbreak of Clostridium difficile 027 infection in Vienna, Austria 2008-2009. Euro Surveill. 2009;14(17):pii=19186. Available from: http://www. eurosurveillance. org/ViewArticle.aspx?Articleld=19186

15. Birgand G, Blanckaert K, Carbonne A, Coignard B, Barbut F, Eckert C, et al. Investigation of a large outbreak of Clostridium difficile PCR-ribotype 027 infections in northern France, 2006-2007 and associated clusters in 2008-2009. Euro Surveill. 2010;15(25):pii=19597. Available from: http://www. eurosurveillance.org/ViewArticle.aspx?Articleld=19597

16. Goorhuis A, Van der Kooi T, Vaessen N, Dekker FW, Van den Berg R, Harmanus C, et al. Spread and epidemiology of Clostridium difficile polymerase chain reaction ribotype 027/toxinotype III in The Netherlands. Clin Infect Dis. 2007.;45(6):695-703.

17. Warny M, Pepin J, Fang A, Killgore G, Thompson A, Brazier J, et al. Toxin production by an emerging strain of Clostridium difficile associated with outbreaks of severe disease in North America and Europe. Lancet. 2005;366(9491):1079-84. 
18. The European Committee on Antimicrobial Susceptibility Testing (EUCAST). Antimicrobial wild type distributions of microorganisms. [Accessed 29 Nov 2010]. Available from: http://217.70.33.99/Eucast2/SearchController/index.jsp;jsess ionid=633Do165AB1D 02892 AF $_{3} 8 E_{1}$ ABCBFC $_{50}$ ?action=initAd vanced

19. Bauer MP, Notermans DW, van Benthem BH, Brazier JS, Wilcox $\mathrm{MH}$, Rupnik M, et al.,Clostridium difficile infection in Europe: a hospital-based survey. Lancet. 2011;377(9759):63-73.

20. Freeman J, Bauer MP, Baines SD, Corver J, Fawley WN, Goorhuis $B$, et al. The changing epidemiology of Clostridium difficile infections. Clin Microbiol Rev. 2010;23(3):529-49.

21. Clements AC, Magalhães RJ, Tatem AJ, Paterson DL, Riley TV. Clostridium difficile PCR ribotype 027: assessing the risks of further worldwide spread. Lancet Infect Dis. 2010;10(6):395-404.

22. Kuijper EJ, van den Berg RJ, Debast S, Visser CE, Veenendaal D, Troelstra A, et al. Clostridium difficile ribotype 027, toxinotype III, the Netherlands. Emerg Infect Dis. 2006;12(5):827-30.

23. Akerlund T, Persson I, Unemo M, Norén T, Svenungsson $B$, Wullt $M$, et al. Increased sporulation rate of epidemic Clostridium difficile Type 027/NAP1. J Clin Microbiol. 2008;46(4):1530-3.

24. Keel K, Brazier JS, Post KW, Weese S, Songer JG.Prevalence of PCR ribotypes among Clostridium difficile isolates from pigs, calves, and other species. J Clin Microbiol. 2007;45(6):1963-4.

25. Debast SB, van Leengoed LA, Goorhuis A, Harmanus C, Kuijper EJ, Bergwerff AA. Clostridium difficile PCR ribotype 078 toxinotype $\mathrm{V}$ found in diarrhoeal pigs identical to isolates from affected humans. Environ Microbiol. 2009;11(2):505-11.

26. Goorhuis A, Bakker D, Corver J, Debast SB, Harmanus C, Notermans DW, et al. Emergence of Clostridium difficile infection due to a new hypervirulent strain, polymerase chain reaction ribotype 078. Clin Infect Dis. 2008;47(9):1162-70.

27. Taori SK, Hall V, Poxton IR. Changes in antibiotic susceptibility and ribotypes in Clostridium difficile isolates from southern Scotland, 1979-2004. J Med Microbiol. 2010;59(Pt 3):338-44.

28. Borgmann, S, Kist M, Jakobiak T, Reil M, Scholz E, von Eichel-Streiber $C$, et al. Increased number of Clostridium difficile infections and prevalence of Clostridium difficile PCR ribotype 001 in southern Germany. Euro Surveill, 2008. 13(49): pii=19057. Available from: http://www.eurosurveillance. org/ViewArticle.aspx?Articleld=19057

29. Brazier JS. Typing of Clostridium difficile. Clin Microbiol Infect. 2001;7(8):428-31.

30. van den Berg RJ, Claas EC, Oyib DH, Klaassen CH, Dijkshoorn $\mathrm{L}$, Brazier JS, et al. Characterization of toxin A-negative, toxin B-positive Clostridium difficile isolates from outbreaks in different countries by amplified fragment length polymorphism and PCR ribotyping. J Clin Microbiol. 2004;42(3):1035-41.

31. Ilchmann C, Zaiss NH, Speicher A, Christner M, Ackermann G, Rohde H. Comparison of resistance against erythromycin and moxifloxacin, presence of binary toxin gene and PCR ribotypes in Clostridium difficile isolates from 1990 and 2008. Eur J Clin Microbiol Infect Dis. 2010;29(12):1571-3.

32. Norén T, Alriksson I, Akerlund T, Burman LG, Unemo M, et al. In vitro susceptibility to 17 antimicrobials of clinical Clostridium difficile isolates collected in 1993-2007 in Sweden. Clin Microbiol Infect. 2010;16(8):1104-10.

33. Terhes G, Urbán E, Sóki J, Szikra L, Konkoly-Thege M, Vollain $M$, et al. Assessment of changes in the epidemiology of Clostridium difficile isolated from diarrheal patients in Hungary. Anaerobe. 2009;15(6):237-40.

34. Biller P, Shank B, Lind L, Brennan M, Tkatch L, Killgore G, et al. Moxifloxacin therapy as a risk factor for Clostridium difficile-associated disease during an outbreak: attempts to control a new epidemic strain. Infect Control Hosp Epidemiol. 2007;28(2):198-201.

35. Deshpande A, Pant C, Jain A, Fraser TG, Rolston DD. Do fluoroquinolones predispose patients to Clostridium difficile associated disease? A review of the evidence. Curr Med Res Opin. 2008;24(2):329-33.

36. Dhalla IA, Mamdani MM, Simor AE, Kopp A, Rochon PA, Juurlink DN. Are broad-spectrum fluoroquinolones more likely to cause Clostridium difficile-associated disease? Antimicrob Agents Chemother. 2006;50(9):3216-9.

37. Novell MJ, Morreale CA. The relationship between inpatient fluoroquinolone use and Clostridium difficile-associated diarrhea. Ann Pharmacother. 2010;44(5):826-31.

38. Bruns AH, Oosterheert JJ, Kuijper EJ, Lammers JW, Thijsen $\mathrm{S}$, Troelstra A, et al. Impact of different empirical antibiotic treatment regimens for community-acquired pneumonia on the emergence of Clostridium difficile. J Antimicrob Chemother. 2010;65(11):2464-71. 